\title{
Zur Naturgeschichte der
}

\section{Sylvia cisticola und Hirundo rufula.}

\author{
Von
}

\author{
Pfarrer W. Pässler.
}

(Hierzu Taf. I. Fig. A. und B.)

I. Sylvia cisticola Temm.

(Cisticola schoenicola Bon.)

Der Cistenrohrsänger, der ungefähr so gross als der Zaunschlüpfer, aber etwas länger und schlanker ist, gehört dem Süden von Europa und dem Norden Afrikas bis Nubien hinab an. Er bauet ins Rohr und Schilf ein so eigenthümliches Nest, dass es mit keinem andern verwechselt werden kann. Rohrstengel und Schilfblätter werden eng mit einander verwebt, die Blätter mit dem Schnabel durchstochen und mit Pflanzenseide zusammengenähet. Das Aeussere hat die Form eines länglichen Beutels, der unten zuweilen zugespitzt ist und frei schwebt. Der Eingang ist entweder oben oder oberhalb auf der Seite.

Die Eier, die Prof. Savi in Toscana gesammelt hat, führen die blasse blaugrüne Farbe, welche die Eier der Musc. luctuosa zeigen, sind aber viel kleiner, (die Eier des Parus caudatus nicht übertreffend,) zartschaliger, feinkörniger, glänzender. Alle, die ich sahe, sind ungleishhälftig, von der allmählich zugerundeten Basis sanft nach der slumpf zugespitzten Höhe abfallend, bald kurzgestaltet, bald gestreckter. Professor Savi schreibt, dass er auch rein weisse Eier des Cistenrohrsängers gefunden habe; aber ein, an $H$. Prof. Thienemann von ihm gesendetes Exemplar ergab sich, wie wir aus dessen Fortpflanzungsgeschichte der Vögel erfahren, und wie der H. Baron von König-Warthausen als Ergebniss eigner Untersuchung des fraglichen Eies mir geschrieben, als das Ei einer Schnecke, welche gerade das Rohrsängernest für ihre Brut gewählt. Gleichwohl ist es richtig, dass S. cisticola glänzend weisse Eier legt. Schrader sandte von Griechenland ein Gelege von 5 Stück an mich ein, uud H. Kunz hat ganz gleiche aus Spanien erhalten.

Ferner hat Hr. von Kö nig mir mitzutheilen die Güte gehabt, dass Hr. Heuglin in Griechenland von dieser Art weisse Eier mit rothen Flecken gefunden. Endlich hat H. v. König lebhaft blaugrüne, stark gefleckte Eier, sammt dem Neste und alten Paare, jüngst aus Sardinien erhalten.

Es ist schwer zu erklären, wie ein und dieselbe Art in verschiedenen Ländern so sehr verschiedene Eier legen könne. Zwar kommen 
von Vögeln, welche einfarbig grüne und weisse Eier legen, auch dergleichen mit rothen Pünktchen vor, wie z. B. rothpunctirte Eier des Gartenröthlings und Kleinspechts; aber hier sind die unscheinbaren, einzelnen Fleckchen eine zufällige, keine charakteristische Zeichnung; jene Eier des Cistenrohrsängers aber sind stark roth gefleckt.

Sollte es etwa mehr als eine Art Cistenrohrsänger geben?

2. Hirundo rufula Temm.

(H. alpestris Pallas, Cecropis melanocrissa Rüppell.)

Unterm 16. Juli 1853 schrieb mir Schrader aus Missolunghi : „Am 8. Juli sahe ich auf dem Gebirge, anderthalb Stunden von Missolunghi, eine kleine Schaar mir unbekannter. Schwalben sich froh im blauen Aether herumtummeln und beobachtete, wie sie zuweilen nach einem Felsen sich herabsenkten und sich von da wieder zur Höhe aufschwangen. Ihr Flug war eigenthümlich, ihre Stimme glich keiner der mir bekannten Schwalbenarten. Ich stieg den Berg hinauf zu dem Felsęn, welcher überhing wie die Decke einer Stube. An der Decke bemerkte ich drei merkwürdig gebaute Nester, zu denen ich hinaufreichen, aber wegen der langen Eingangsröhre weder hineinsehen, noch hineingreifen konnte. Bei dem Versuche, ein Nest mit dem Messer vom Felsen zu trennen, brach ein Stück vom Neste los; da entflogen ihm zwei völlig flügge Junge, eins fing ich und ein unausgebrütetes Ei fand ich im Neste. In den andern Nestern' waren die Jungen noch zu wenig ausgebildet. Zwei Tage darauf entdeckte ich in der Nähe jenes Felsens eine ziemliche Anzahl Nester von derselben Bauart, aus denen die Jungen schon ausgeflogen waren, und erlegte einen alten Vogel."

Die Beschreibung, welche Schrader von den Vögeln machte, liess auf H. rufula schliessen, und die eingesendeten Vögel bestätigten diese Vermuthung. Ich erhielt nämlich durch Schrader einen alten und einen jungen Vogel, welche sich zur Zeit in der Sammlung des Herrn Majors von Zittwitz zu Glogau befinden, und jenes bei den flüggen Jungen gefundene Ei, welches ich noch besitze. Im folgenden Jahre erbeutete und übersendete Schr. 14 Eier.

Ich lasse nun die überkommenen Beschreibungen der Vögel und des Nestes fulgen.

Der alte Vogel (ob Männchen oder Weibchen ist ungewiss, da die Geschlechtstheile durch den Schuss zerstört worden) misst von der Schnabelspitze bis zur längsten Schwanzfeder 7" $21 / 2^{\prime \prime \prime}$. Der Schnabel, die Füsse und Krallen sind schwärzlich. Der Oberkopf zeigt eine blauschwarze Platte; von der Schnabelwurzel zieht sich ein schmaler, röthlich gelber Streif bis zum Auge; von da läuft der lebhafter gefärbte 
Streif um die Kopfplatte und bildet im Nacken ein breites Band. Die Ohrengegend und Seiten des Halses sind röthlich; Kehle und untere Seite des Halses heller gefärbt und mit feinen dunkeln Schaftstrichen durchzogen. Dieselbe Farbe, mit stärker hervortretenden Schaftstrichen, bedeckt den obern Theil der Brust. Die Seiten unter den Flügeln sind blass rothgelblich, nach dem Brustbein hin heller verschwimmend bis ins Weissliche. Gleiche Färbung zeigt auch der Unterleib. Die Unterschwanzdeckfedern sind schwarz, stahlblau überlaufen, die kleinsten mit gelblicher Einfassung; die Unterseite des gabelförmigen Schwanzes ist grauschwarz. Die längste Schwanzfeder, $3^{\prime \prime} 3^{1} / 2^{\prime \prime \prime}$ lang, (vom Ende des Kiels bis zur Spitze gemessen), hat in der Mitte einen grossen weissen Fleck, der von unten nicht so rein erscheint. Oberschwanz und Oberschwanzdeckfedern dunkel mit grünlichem Schimmer. Von den Oberschwanzdeckfedern läuft zum Rücken ein blassröthlichgelber, 11"' breiter Streif. Ober - und Unterrücken bis zum röthlichen Nackenbande schwarz, stahlblau überlaufen. Die Schwungfedern, von denen die äusserste die längste ist, dunkel grünlich schimmernd, die vier längsten ohne Einfassung, die übrigen heller eingefasst. Die grossen Oberflügeldeckfedern, wie die kleinern des Bugs, sind hellgelblich gesäumt. Die Mitte des Flügels zeigt einen schmalen gelblichen Streif, der durch den Saum der Aussenfahne der kleinern Deckfedern gebildet wird. Die Unterflügel am Bug röthlich gelb, übrigens grauschwarz. Der Schaft der grossen Schwungfedern ist oben schwärzlich, auf der andern Seite weisslich.

Die jungen Vögel sehen den alten sehr ähnlich, nur sind Schnabel und Füsse heller, und es fehlt der weisse Fleck auf der Mitte der äussersten Schwanzfedern. Die Iris ist dunkelbraun, der Rachen hellgelb.

Die Nester dieser Schwalben sind nach Art der Hausschwalben-Nester gebauet, haben aber einen langen Hals als Eingang und sonach eine Form, wie die Nester der Sitta syriaca. Ihre Umkleidung besteht aus zusammengeklebten Klümpchen von Lehmerde, da mit sind sie auch an die überhängende Felsdecke festgekittet. Im Innern ist eine Unterlage feiner trockner Grashälmchen, darauf eine weiche Auskleidung von weisser filzähnlicher, durch einander gewirrter Wolle. Die Länge der Eingangsröhre eines an Ort und Stelle gemessenen Nestes - Fig. A. - , beträgt $3^{\prime \prime} 9^{\prime \prime \prime}$, der Eingang selbst ist $2^{\prime \prime} 1^{\prime \prime \prime}$ hoch und $2^{\prime \prime} 9^{\prime \prime \prime}$ breit. Der grösste Durchschnitt des beutelförmigen Nestes misst 10", der geringste $8^{\prime \prime}$; die Mitte des innern Napfes $3^{\prime \prime} 7^{\prime \prime \prime}$ als grösste Tiefe.

Von den erhaltenen 15 Eiern nun ist das grösste $72 / 3^{\prime \prime \prime}$ lang und $5^{1} / 3^{\prime \prime \prime}$ breit, das kleinste $7^{1} / 8^{\prime \prime \prime}$ lang und $5^{1} / 8^{\prime \prime \prime}$ breit. Alle sind ungleich- 
hälftig und gestreckt, der grösste Durchmesser nach der Basis zu liegend, von welchem aus das Ei nach der Basis allmählich, nach der Höhe stark abfällt. Jene ist sanft zugerundet, diese stumpf zugespitzt. Sie haben eine zarte, sehr feine, glänzende Schale und sehen schneeweiss aus. Den Hausschwalbeneiern sind sie an Grösse und Gestalt sehr ähnlich, unterscheiden sich aber durch die feinere, glänzende Oberfläche und durch das reinere Weiss.

Gegen die Aechtheit des einfarbig weissen Eies hegten sowohl mein verehrter Freund Herr Bädeker, als auch der Herr Baron von Kö nig Zweifel. Und allerdings konnte man von dieser Schwalbe, wegen ihrer nahen Verwandtschaft mit $H$. rustica, gefleckte Eier erwarten. Meine eignen $\mathrm{Zweifel}$ waren durch die bestimmtesten Versicherungen und ausführlichsten Auseinandersetzungen Schraders: dass die Eier sicher der H. rufula angehörten, gefallen; H. Bädeker erkannte die Aechtheit derselben an, nachdem er die Vögel gesehen; und vor wenigen Tagen schrieb mir H. von König, dass die Eier schon von Pallas als.weiss beschrieben, und $H$. Prof. Thien emann, dem er das von mir erhaltene Ei überschickt, ihm erwiedert habe, dass er gleiche Eier und unter demselben Namen anderswoher empfangen hätte. So sind denn die Zweifel zu allseitiger Zufriedenheit gehoben und für die Naturgeschichte der $\boldsymbol{H}$. rufula wichtige Momente gewonnen.

Brambach, den 25. Februar 1857.

\section{Briefliche Mittheilungen und Fenilleton.}

\section{Notiz iber seltne Vägel am Amur.}

(Auszug aus einem Briefe des Herrn Staatsrath Professor Dr, Br a nd t in Petersburg d. d. 20. Febr. 1857 an Hrn. Geh. Rath Prof. Dr. H. Lichtenstein.)

„An den Ufern des Flusses Amur hat man Anas galericulata wild gefunden. Hirundo Ciris Pall. ist auch wieder entdeckt. - Neue Vögel sind etwa drei vorhanden, darunter ein interessanter, meinem altaicus verwandter Accentor." 